\title{
Enhancing the Internal Representation of the Body Through Sensorimotor Training in Sports and Dance Improves Balance Control
}

ISSN: 2577-1914

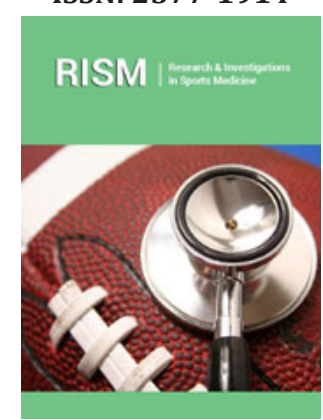

*Corresponding author: Marie Fabre, Aix-Marseille Univ, CNRS, Laboratoire de Neurosciences Cognitives, 3 place Victor Hugo 13331 Marseille Cedex 3, France

Submission: 眥 December 20, 2019

Published: 侮February 19, 2020

Volume 6 - Issue 1

How to cite this article: Marie Fabre, Jean Blouin, Laurence Mouchnino. Enhancing the Internal Representation of the Body Through Sensorimotor Training in Sports and Dance Improves Balance Control. Res Inves Sports Med, 6(1): 469-473. DOI: $10.31031 /$ RISM.2020.06.000629

Copyright@ Marie Fabre, This article is distributed under the terms of the Creative Commons Attribution 4.0 International License, which permits unrestricted use and redistribution provided that the original author and source are credited.

\author{
Marie Fabre*, Jean Blouin and Laurence Mouchnino
}

Aix Marseille Univ, CNRS, Laboratoire de Neurosciences Cognitives, FR 3C, Marseille, France

\begin{abstract}
Body internal representation (BIR) is built up from the integration of sensory signals and is essential to control movement and balance. Here we review different types of trainings involving sensorimotor experiences that improve the BIR accuracy, balance and movement production.
\end{abstract}

Keywords: Body internal representation; Balance control; Proprioception; Sensorimotor training

Abbreviations: APA: Anticipatory Postural Adjustment; BIR: Body Internal Representation; TPJ: Temporo-Parietal Junction

\section{Introduction}

Postural or balance control is of paramount importance for motor actions such as standing or walking. Interestingly preserving balance or body orientation while a voluntary movement is performed implies prediction of the postural disturbances provoked by the movement itself [1]. Indeed, limb or trunk movements induce a shift of body's center of mass that can disturb balance if not compensated prior to their execution [2]. Such anticipated control of balance is grounded on the capacity of the brain to use a body internal representation (BIR) in space $[3,4]$. The BIR is built up and updated from multisensory integration involving proprioceptive, tactile, vestibular, visual inputs and is referred relative to a stable reference frame such as gravity. For example, the updating of the BIR through labyrinthine and muscle proprioceptive Ia inputs allows the fine tuning of the postural reactions following body disturbance [5]. It is worth noting that despite being important for calibrating proprioceptive inputs, visual information appears to be less involved than somatosensory for the fast updating of the body parts or whole-body position in space (i.e. BIR) required for enabling appropriate postural reactions. In this review, we will explore how the accuracy of the BIR can be improved by sensorimotor experience enabled by the practice of physical activities. We will particularly focus on activities that involve knowledge of the body parts' relative motion and that require keeping or disrupting the vertical alignment of the body.

\section{Discussion}

Studies during the past three decades have demonstrated that dance or dance-like training improves the accuracy of the BIR [6-9] and changes balance control (i.e. anticipatory postural adjustments, APAs) associated with motor performance [10,11]. For example, Mouchnino et al. [11] showed that in dancers (over 15 years of modern dance practice and on-stage experience), the APAs prior to leg raising are highly accurate and do not necessitate online adjustments. The relative timing between the APAs and their movements of the leg also shows little variation. In non-trained participants, the APAs prior to leg raising are associated with greater online adjustments. This suggests that dance training allows developing an accurate internal representation of the body dynamics, which in turn enhances the use of an anticipated mode of movement control. While the "sculpting" of the BIR through highlevel dance training is undisputed, some studies have shown that remodeling the BIR can occur within a few weeks of practice, even in participants with no regular physical activities. For example, creative dance programs using body communication through movements emphasizing body awareness (12 weeks with a periodicity of 3 sessions of 90 min per 
week) improve the accuracy of joint movement detection in sedentary participants over 55 years of age [9]. Sensing ankle joint movements is particularly important for postural control as it allows detecting whole body movement relative to vertical. In T'ai Chi Chuan, a discipline where awareness of each body part position is emphasized during slow and precise movements, balance control also rapidly improves in new adherents (12 weeks training, 3 times a week [12] as well as in participants over 65 years of age with one to twenty years of practice [13]).

While dance exercises most often involve healthy individuals, the technique of Gerda Alexander was initially developed to find ways to move without exacerbating pain. It is after contracting rheumatism that this woman designed this technique that first aims at regulating muscle tone (i.e. eutony based exercises) and improving self-awareness (i.e. the ability to notice and feel sensations in the body). As was observed in dancers [11], the Gerda Alexander's method practitioners (i.e. teachers who had completed a 1,600-h course certified by the Society of Teachers of the Alexander Technique) show a change in the APAs when they get up slowly from a seated position [10]. In highly trained participants, this daily life motor behavior is accomplished by a smooth and prolonged weight shift forward to the feet contrary to the jerkiness way used by nontrained participants. Enhancing bodily and sensory awareness (i.e. embodiment), this training would help reducing the leg joints' stiffness which can hamper the center of mass from travelling sufficiently far forward to get off the chair easily. Interestingly, after having participated in an 8-week program of MindfulnessBased Stress Reduction (which emphasizes body awareness as the Alexander technique), individuals showed an increase in grey matter concentration in the temporo-parietal junction (TPJ, [14]). This cortical area is known to host the conscious experience of the self or embodiment $[15,16]$. This is in line with studies assigning roles to the TPJ in different aspects of the BIR (e.g., perception of body parts [17]; mental imagery of one's body [18,19]). Together, these findings suggest that motor and cognitive activities focusing on body awareness (e.g., dance, Alexander and T'ai Chi Chuan training) can improve balance and movement control by enhancing the BIR in space.

In the forms of practice reviewed above, the improvement of the BIR is based on the sensorimotor experience of self-triggered movements. Other physical practices, which specifically target balance recovery to imposed perturbations, can help shortening the resetting time of the BIR. For example, Wang et al. [20] showed that highly trained judokas (black belts judoka involved in national and international athletic tournaments) improve balance control as compared to non-trained participants. In this physical activity, particular attention is given on proprioceptive information involving receptors implicated with conscious sensations including the senses of limb position and movement, the sense of tension or force, and the sense of balance (for a review, see [21]). It is also clear that the sense of balance, primarily subserved by the vestibular and foot sole tactile receptors is targeted by judo training. These two types of exteroceptors provide information about the body's orientation relative to gravity and the location of the body center of mass with respect to the body surface in contact with the ground [2]. Together with exteroception, a major role of proprioception in the resetting of the BIR has been highlighted by showing that the representation of the limb in the motor cortex changes with body posture [22-24]. A shorter sensorimotor training focused on balance recovery from external perturbation could also change the quality of the BIR as evidenced by a change in balance control [25]. These authors showed that balance stability is improved by stimulating proprioceptive afferences during a short training period ( 4 weeks, 4 times a week) consisting in different exercises on an unstable support (i.e. wobbling boards, spinning tops and different kinds of soft mats and cushions). In addition, modification of the APAs which rely on the use and the quality of an internal representation of the body position in space [26] can occur after similar short training. This is observed in patients with chronic pain who's APAs are known to be delayed $[27,28]$. For instance, Hwang et al. [28] showed that the APAs prior to arm flexion occur earlier in patients who followed an intervention program based on exercises performed in a quadrupedal stance or in a supine position on a wobble board (i.e. an unstable disk perched on half a ball) (40min sessions, five times a week during 4 weeks) than in patients who subscribed to classic physical therapies over the same period of time. Surprisingly, highly trained athletes also benefit from short specific proprioceptive training. This has been shown in Olympic windsurfers that used either a dry-land proprioceptive training (3 times a week for 6 weeks) or a fitness training, in addition to their outdoors training [29]. Although athletes of both groups were highly trained and skilled in maintaining their equilibrium on an unstable support, only those who have benefited from the proprioceptive training significantly improved their balance control. The increased ability to rapidly trigger adapted postural responses to external perturbations is consistent with an enhancement of the BIR after a training focused on proprioceptive information processing (e.g., judo, wobble board).

\section{Conclusion}

To conclude, this mini review showed that either long-term training or short periods of practice might improve the accuracy of the BIR in space. Such training, based on sensorimotor tasks that highly involved body sensation, could be relevant for motor rehabilitation after injuries or in patients suffering from balance impairments (e.g. parkinsonians or obese patients).

\section{Conflict of Interest}

None of the authors have potential conflicts of interest to be disclosed.

\section{References}

1. Massion J, Woollacott MH (1996) Posture and equilibrium. (2 $2^{\text {nd }}$ end), Clinical Disorders of Balance, Posture and Gait, Arnold, London, UK, pp. 1-19.

2. Massion J (1992) Movement, posture and equilibrium: interaction and coordination. Prog Neurobiol 38(1):35-56. 
3. Wolpert DM (1997) Computational approaches to motor control. Trends in Cognitive Sciences 1(6): 209-216.

4. Frith CD, Blakemore SJ, Wolpert DM (2000) Abnormalities in the awareness and control of action. Philos Trans R Soc Lond B Biol Sci 355(1404): 1771-1788.

5. Popov KE, Kozhina GV, Smetanin BN, Shlikov VY (1999) Postural responses to combined vestibular and hip proprioceptive stimulation in man. European Journal of Neuroscience 11(9): 3307-3311.

6. Golomer EM, Gravenhorst RM, Toussaint Y (2009) Influence of vision and motor imagery styles on equilibrium control during whole-body rotations. Somatosensory \& Motor Research 26(4): 105-110.

7. Calvo-Merino B, Glaser DE, Grèzes J, Passingham RE, Haggard P (2005) Action observation and acquired motor skills: An fMRI study with expert dancers. Cerebral Cortex 15(8): 1243-1249.

8. Calvo-Merino B, Urgesi C, Orgs G, Aglioti SM, Haggard P (2010) Extrastriate body area underlies aesthetic evaluation of body stimuli. Experimental Brain Research 204(3): 447-456.

9. Marmeleira JF, Pereira CLN, Cruz-Ferreira A, Fretes V, Pisco R, et al (2009) Creative dance can enhance proprioception in older adults. Journal of Sports Medicine and Physical Fitness 49(4): 480-485.

10. Cacciatore TW, Mian OS, Peters A, Day BL (2014) Neuromechanical interference of posture on movement: evidence from Alexander technique teachers rising from a chair. J Neurophysiol 112(3): 719-729.

11. Mouchnino L, Aurenty R, Massion J, Pedotti A (1992) Coordination between equilibrium and head-trunk orientation during leg movement: a new strategy build up by training. J Neurophysiol 67(6): 1587-1598.

12. Jacobson BH, Ho-Cheng C, Cashel C, Guerrero L (1997) The effect of T'ai Chi Chuan training on balance, kinesthetic sense, and strength. Percept Mot Skills 84(1): 27-33.

13. Tse SK, Bailey DM (1992) T'ai chi and postural control in the well elderly. The American Journal of Occupational Therapy 46(4): 295-300.

14. Hölzel BK, Carmodyc J, Vangela M, Congletona C, Yerramsettia SM, et al. (2011) Mindfulness practice leads to increases in regional brain gray matter density. Psychiatry Research 191(1): 36-43.

15. Blanke 0, Arzy S (2005) The out-of-body experience: disturbed selfprocessing at the temporo-parietal junction. Neuroscientist 11(1): 1624.

16. Arzy S, Thut G, Mohr C, Michel CM, Blanke O (2006) Neural basis of embodiment: distinct contributions of temporoparietal junction and extrastriate body area. J Neurosci 26(31): 8074-8081.
17. Bonda E, Petrides M, Frey S, Evans A (1995) Neural correlates of mental transformations of the body-in-space. Proceedings of the National Academy of Sciences 92(24): 11180-11184.

18. Ionta S, Heydrich L, Lenggenhager B, Mouthon M, Fornari E, et al. (2011) Multisensory mechanisms in temporo-parietal cortex support selflocation and first-person perspective. Neuron 70(2): 363-374.

19. Wang H, Callaghan, E, Gooding-Williams, G, McAllister C, Kessler K (2016) Rhythm makes the world go around: An MEG-TMS study on the role of right TPJ theta oscillations in embodied perspective taking. Cortex 75: 68-81.

20. Perrin P, Deviterne D, Hugel F, Perrot C (2002) Judo, better than dance, develops sensorimotor adaptabilities involved in balance control. Gait \& Posture 15(2): 187-194.

21. Proske U, Gandevia SC (2012) The proprioceptive senses: Their roles in signaling body shape, body position and movement, and muscle force. Physiological Reviews 92(4): 1651-1697.

22. Armstrong DM, Drew T (1985) Electromyographic responses evoked in muscles of the forelimb by intracortical stimulation in the cat. J Physiol 367(1): 309-326.

23. Sanes JN, Wang J, Donoghue JP (1992) Immediate and delayed changes of rat motor cortical output representation with new forelimb configurations. Cerebral Cortex 2(2): 141-152.

24. Graziano MS, Patel KT, Taylor CS (2004) Mapping from motor cortex to biceps and triceps altered by elbow angle. J Neurophysiol 92(1): 395407.

25. Taube W, Gruber M, Beck S, Faist M, Gollhofer A (2007) Cortical and spinal adaptations induced by balance training: correlation between stance stability and corticospinal activation. Acta Physiol (Oxf) 189(4): 347-358.

26. Assaiante C, Chabeauti PY, Sveistrup H, Vaugoyeau M (2011) Updating process of internal model of action as assessed from motor and postural strategies in young adults. Human Movement Science 30(2): 227-237.

27. Hodges PW, Richardson CA (1999) Altered trunk muscle recruitment in people with low back pain with upper limb movement at different speeds. Arch Phys Med Rehabil 80(9): 1005-1012.

28. Hwang JA, Bae SH, Do Kim G, Kim KY (2013) The effects of sensorimotor training on anticipatory postural adjustment of the trunk in chronic low back pain patients. J Phys Ther Sci 25(9): 1189-1192.

29. Linares R, Micallef JP, Marin L (2012) Proprioceptive training improves the balance of Olympic windsurfers. Science \& Sports 27(5): 283-292.

For possible submissions Click below:

Submit Article 